\title{
What You See Is What You Get—But Not Always
}

Medicine in the modern era is transforming faster than many had likely anticipated, literally opening doors to types of care previously unimagined. Six years ago, a group of medical professionals with interests in austere medicine attending a Special Operations Medical Association Conference demonstrated remote operation of a mechanical ventilator in Israel, with the same accuracy as if controlled at the location. As advanced as that may have seemed, the technical aspects were largely commonplace, if not rudimentary given today's wireless communication capabilities. What is not as simplistic are the challenges posed by critical care medicine and the safeguards required when one cannot physically see a device, as in the aforementioned scenario.

The prospects of telemedicine continue to enhance and confound the delivery of health care, asserting more efficient, timely, less costly care, while the potential pitfalls are yet to be fully elucidated. It is certain that, in many cases, delivery of care would be minimized, if not inaccessible, due to a variety of constraints, which makes providing health care from a distance that much more attractive. For many, it is likely a life-sustaining mediation, as is the case for those requiring mechanical ventilation in the home, relying on caregivers from afar to ensure the safety and efficacy of interventions.

Executing good medical interventions assumes the plan is appropriate, accurate, and reproducible. The introduction of remote/telemedicine requires additional measures to ensure the "medicine" we intend to deliver is the medicine received. Despite advances in mechanical ventilation coupled with oxygen delivery, the onus still rests with the provider for accurate delivery, and in the absence of visual assurance, not everything is intuitive.

Lewarski and Gay ${ }^{1}$ indicated that evidence-based standards of care for the application of invasive mechanical ventilation in the home are nonexistent. It is difficult to ascertain the impact of mechanical ventilation in homes

\footnotetext{
The views expressed are those of the author and do not necessarily reflect the official policy or position of the Air Force, the Department of Defense, or the U.S. Government.

Correspondence: Dario Rodriquez Jr MSc RRT FAARC, University of Cincinnati, Department of Surgery, 231 Albert Sabin Way, Suite 2108D, Cincinnati, OH 45267. E-mail: dario.rodriquez@uc.edu.
}

DOI: $10.4187 /$ respcare. 07714 because data are limited, absent any significant central accounting for either invasive or noninvasive ventilation. A consensus report generated by the American College of Chest Physicians in 1998 estimated that 10,000-20,000 patients utilized mechanical ventilation in their homes. ${ }^{1}$

\section{See the Original Study on Page 288}

In a small prospective trial evaluating 12 ventilator dependent children discharged from a pediatric ICU, MuñozBonet et $\mathrm{al}^{2}$ surmised a potential value in telemedicine, expressing its utility in early discharge to home without compromising quality of care. Of particular note was their inclusion of the families' characterization of tending to a loved one at home. Though all conveyed that their training was sufficient, half expressed apprehension; this is a potential gap, given that the surrogate caregiver (eg, a parent or a spouse) assumes a certain safety capacity to reassure the patient that he or she is not going without the attention of a medical professional.

Oxygen delivery during mechanical ventilation at home commonly requires an oxygen concentrator and a lowflow source delivered into the circuit or the inlet of the driving system. The addition of oxygen into the inspiratory limb of the circuit is commonly accomplished, but it has well-known effects on the delivered tidal volume $\left(\mathrm{V}_{\mathrm{T}}\right)$. Others have sought to maximize oxygen efficiency and limit the impact on $\mathrm{V}_{\mathrm{T}}$ delivery. ${ }^{3}$ Rodriquez et al ${ }^{4}$ illustrated a potential solution for incorporating pulse dose oxygen delivery into the ventilator circuit considered for home ventilation applications; at least one commercial device utilizes this technology (VOCSN, Ventec Life Systems, Bothell, Washington).

In this issue of the Journal, d'Aranda et $\mathrm{al}^{5}$ highlight augmentation of the set $\mathrm{V}_{\mathrm{T}}$, the well-documented consequence of adding oxygen into the inspiratory limb. They further describe the impact of various flows at the ventilator inlet, which had not been published previously. As noted, flow introduced into the inspiratory limb of the ventilator circuit may introduce unintentioned consequences, in this case as much as a $29 \%$ increase in $\mathrm{v}$ for the highest oxygen flow tested (ie, $8 \mathrm{~L} / \mathrm{min}$ ). This flow is likely not commonly observed in home care, but it might be seen in austere environments including military and disaster 


\section{EDITORIAL}

response. The results of the study are not unique, unexpected, or particularly complicated. The addition of flow into the circuit might also adversely impact triggering.

What the work by d'Aranda et $\mathrm{al}^{5}$ does bring to light is the impact of oxygen delivery practices on "data" and "information" available remotely to caregivers. This is a very basic type of telemedicine, where the caregiver can evaluate the ventilator settings, measured values, and infer the status of the patient. The information transferred remotely to providers would be assumed to be accurate. However, without an awareness of how the oxygen was delivered, medical decisions could be made with an inappropriate and incomplete understanding of delivered $\mathrm{V}_{\mathrm{T}}$. Evidencebased practice is only possible when the health care system is cognizant of reliable data, and making a decision as to whether to adjust ventilatory support requires a reasonable accounting of dose-specific interventions. In this case, "what you see is what you get" is not operable. Even in cases where oxygen does not supplement mechanical ventilation delivery, accuracy of the data may be suspect. A bench study by Luján et $\mathrm{al}^{6}$ evaluated the operational characteristics of 5 commercial ventilators providing noninvasive ventilation under varying conditions of leak and ventilatory pattern. Their efforts resulted in identifying an underestimation of delivered $\mathrm{V}_{\mathrm{T}}$ in all systems by as much as $15 \% .^{6}$ It is important to note that, in their work, at least one system capitalized on the utility of a predictive algorithm for pressure loss in the circuit, resulting in a disparity in volume estimation of only $0.3 \%$.

A hallmark of respiratory therapy beginning with the origins of the profession is problem-solving. In many instances, this involves the modification of devices to address shortcomings related to design and site of care. Consider only the early continuous positive airway pressure and intermittent mandatory ventilation systems to remind you of the ingenuity of early therapists. This study by d'Aranda et $\mathrm{al}^{5}$ demonstrates that, depending on the site of oxygen supplementation, the site of $\mathrm{V}_{\mathrm{T}}$ measurement, and the accuracy of the sensor, important differences in actual and reported $V_{T}$ may occur. In the current regulatory and legal environment, modification of devices is less commonplace. However, necessity is the mother of invention, and caregivers are challenged in home and austere environments to meet patient requirements. This paper highlights a concern with the use of telemedicine to transmit inaccurate data.

The promise of telemedicine and "big data" relies on a host of complex factors. Importantly, the accuracy of the reported data are paramount. These issues can inform our practice and serve as a cautionary tale for unintended consequences of modifications to existing devices. Medical errors are often described using the "Swiss cheese" model. $^{7}$ That is, there is typically not a single factor resulting in an untoward outcome. This issue is no different. The use of oxygen added to the inspiratory limb, the position of the flow sensor in the circuit, training of the caregivers, and the transfer of inaccurate data have the potential to lead to inappropriate decisions. The role of the respiratory therapist in home ventilation is to close the holes in the Swiss cheese.

\section{Dario Rodriquez Jr \\ Department of Surgery \\ University of Cincinnati \\ Cincinnati, Ohio}

\section{REFERENCES}

1. Lewarski JS, Gay PC. Current issues in home mechanical ventilation. Chest 2007;132(2):671-676.

2. Muñoz-Bonet JI, López-Prats JL, Flor-Macián EM, Cantavella T, Bonet L, Domínguez A, Brines J. Usefulness of telemedicine for home ventilator-dependent children. J Telemed Telecare 2018: 1357633 X1881175.

3. Blakeman T, Rodriquez D, Johannigman J, Branson R. Pulsed dose oxygen delivery during mechanical ventilation: impact on oxygenation. Mil Med 2019;184(5-6):e312-e318.

4. Rodriquez D Jr, Blakeman TC, Dorlac W, Johannigman JA, Branson RD. Maximizing oxygen delivery during mechanical ventilation with a portable oxygen concentrator. J Trauma 2010;69(1):S88-S93.

5. d'Aranda E, Cungi P-J, Mathais Q, et al. The site of oxygen delivery into a home ventilator impacts recorded volumes. Respir Care 2020;65 (3):288-292.

6. Luján M, Sogo A, Pomares X, Monsó E, Sales B, Blanch L. Effect of leak and breathing pattern on the accuracy of tidal volume estimation by commercial home ventilators: a bench study. Respir Care 2013;58 (5):770-777.

7. Reason J. Human error: models and management. BMJ 2000;320 (7237):768-770. 